\title{
Pathophysiological Implications of RNP Granules in Frontotemporal Dementia and ALS
}

\author{
Perlina Desai ${ }^{\mathrm{i}^{*}}$, Rina Bandopadhyay ${ }^{\mathrm{b}}$
}

${ }^{a}$ Alzheimer's Research UK UCL Drug Discovery Institute and Department of Neuromuscular Diseases. University College London, The Cruciform Building, Gower Street, London, WC1E 6BT, UK, perlina.desai.17@ucl.ac.uk

${ }^{\mathrm{b}}$ Reta Lila Weston Institute of Neurological Studies and Department of Clinical and Movement Neuroscience. University College London, Queen Square Institute of Neurology, 1 Wakefield Street, London, WC1N 1PJ, UK, rina.bandopadhyay@ucl.ac.uk

*Corresponding author at Alzheimer's Research UK UCL Drug Discovery Institute and Department of Neuromuscular Diseases. University College London, The Cruciform Building, Gower Street, London, WC1E 6BT, UK, perlina.desai.17@ucl.ac.uk 


\begin{abstract}
Neurodegenerative diseases are a group of chronic, progressive, age-related disorders that are becoming increasingly prevalent in the ageing population. Despite the variety of clinical features observed, neurodegenerative diseases are characterised by protein aggregation and deposition at the molecular level. The nature of such intracellular protein aggregates is dependent on disease type and specific to disease subtype. Frontotemporal dementia and amyotrophic lateral sclerosis (ALS) are two overlapping neurodegenerative diseases, exhibiting pathological aggregates commonly composed of the proteins: Fused in Sarcoma (FUS) or Transactive Response DNA Binding Protein of 43 KDa (TDP-43). The presence of these protein aggregates in late disease stages is suggestive of a converging underlying mechanism of pathology across diseases involving disrupted proteostasis. Despite this, at present there are no effective therapeutics for the diseases, with current treatment strategies generally tending to be only for symptom management. An area of research that has gained increased interest in recent years is the formation and maintenance of ribonucleoprotein (RNP) granules. These are membraneless organelles that consist of RNA and protein elements, which can be either constitutively expressed (such as nuclear paraspeckles) or upregulated under conditions of cellular stress as an adaptive response (such as cytoplasmic stress granules). RNA-binding proteins are a key component of RNP granules, and crucially some of which, for example FUS and TDP-43, are also neurodegenerative disease-associated proteins. Therefore, a better understanding of RNAbinding proteins in RNP granule formation and the regulation and maintenance of RNP granule biophysical properties and dynamics may provide insights into mechanisms contributing to disrupted proteostasis in neurodegenerative pathology; and thus open up new avenues for therapeutic discovery and development. This review will focus on stress granule and paraspeckle RNP granules, and discuss their possible contribution to pathology in cases of frontotemporal dementia and ALS.
\end{abstract}

\title{
Keywords
}

stress granule, paraspeckle, RNA-binding protein, FUS, TDP-43, neurodegeneration

\section{Introduction}

Neurodegenerative disease encompasses a diverse range of chronic, progressive, agerelated neurological diseases with wide-ranging clinical symptoms (Erkkinen et al., 2018). Not only are they a major health burden due to their increasing prevalence in the population, but there are also clear associated social and economic impacts. At present no effective disease-modifying therapeutics exist and current treatment strategies tend to be supportive and for symptom management (Gan et al., 2018).

Neurodegenerative diseases are multi-faceted with a highly complex aetiology.

Frontotemporal dementia and amyotrophic lateral sclerosis (ALS) are two neurodegenerative diseases with overlapping genetic aetiologies, pathological and clinical features (Gao et al., 2017). At a molecular level, the presence of aggregated proteins 
forming persistent intracellular inclusions is a common feature (Arai et al., 2006; Neumann et al., 2006; 2009). Although the nature of such inclusions is specific to disease type, the presence of inclusions is a shared feature across diseases which suggests a failure of protein homeostasis (proteostasis) mechanisms may be involved in driving this age-related pathology (Aguzzi et al., 2010; Wyss-Coray., 2016). There is a clear and currently unmet need to better understand such underlying mechanisms of neurodegenerative pathology in order to identify novel targets and develop effective therapeutics to combat these devastating diseases.

An exciting area of research that has gained increased interest in recent years is the formation and regulation of the membraneless organelles, ribonucleoprotein (RNP) granules. RNP granules provide temporal and spatial organisation and control of protein translation across cellular compartments. Therefore, improving the efficiency of biochemical processes within cells and thus ultimately conferring a cytoprotective role (Boeynaems et al., 2018). In the cytoplasm, stress granules and processing bodies are types of RNP granules, whereas paraspeckles, Cajal bodies and nucleoli, are examples of nuclear RNP granules. Membraneless organelles are thought to carry out diverse functions such as regulating gene expression and the cellular response to stress (Verdile et al., 2019). However, it is vital that these processes are carefully regulated as changes to the biophysical properties and dynamics of RNP granules may result in increased protein insolubility, hence possibly leading to the formation of persistent inclusions (Alberti et al., 2017; Formicola et al., 2019). In this way, dysregulation of the maintenance of RNP granules may provide a possible mechanism contributing to disrupted proteostasis in neurodegenerative disease. This review will focus on two RNP granules namely, stress granules and paraspeckles, and explore their potential pathological role in neurodegeneration using frontotemporal dementia and ALS as disease examples.

\section{RNP granules}

\subsection{Stress Granules}

Cells are constantly exposed to various stresses, such as thermal, osmotic, oxidative or endoplasmic reticulum (ER) stress. It is vital to effectively regulate and activate cellular response pathways to ensure that cell viability and functionality is maintained. Stress granules are dynamic cytoplasmic RNP granules that rapidly assemble under conditions of stress. The stress induces the phosphorylation of elF $2 \alpha$, or inhibition of elF4A, ultimately resulting in repression of global translation. Stress granule formation is an important, protective response enabling resources to be conserved under stressful conditions by sequestering non-essential transcripts. Once the stress has been overcome, stress granules are stimulated to rapidly disassemble through dephosphorylation of elF $2 \alpha$, and translation of mRNA transcripts can thus recommence (Kedersha et al., 1999; Anderson and Kedersha, 2006; 2008; Mokas et al., 2009).

Although the composition of stress granules can vary depending upon the type of stress stimulating their formation, they typically consist of non-translating mRNAs, stalled preinitiation complexes and RNA-binding proteins (Anderson and Kedersha, 2006; 2008; Buchan et al., 2011; Jain et al., 2016; Aulas et al., 2017; Markmiller et al., 2018). Electron 
microscopy and super-resolution imaging techniques have enabled the structure of stress granules to be probed. This has led to the observation that they are electron-dense and structurally non-uniform, consisting of an inner stable "core", and a more dynamic outer "shell". Purification of stress granules and subsequent transcriptomic and proteomic analyses have suggested that the core is composed of a high protein and RNA concentration, while the shell, which weakly interacts with the core, appears to contain a low concentration of protein and RNA components (Buchan and Parker, 2009; Souquere et al., 2009; Jain et al., 2016; Khong et al., 2017). This core-shell structure of stress granules is summarised in Figure 1a.

Assembly of stress granules is thought to occur via protein-protein interaction of mRNA with bound proteins and RNA-binding proteins (Jain et al., 2016). T Cell Internal Antigen-1 Related Protein (TIAR), Ras GTPase-activating Protein SH3 Domain-Binding Protein (G3BP), and T Cell Intracellular Antigen 1 (TIA 1) are examples of such RNA-binding proteins that promote stress granule formation and hence act as characteristic stress granule markers. However, these RNA-binding proteins are not necessarily required for stress granule formation, and appear to selectively promote stress granule assembly, perhaps through different protein-protein interactions (Kedersha et al., 1999; Tourrière et al., 2003; Protter and Parker, 2016). For example, G3BP is required in the formation of stress granules under conditions of oxidative but not osmotic stress or heat shock (Tourrière et al., 2003; Kedersha et al., 2016). This illustrates the redundant and the context-specific nature of stress granule formation, with the multitude of interactions by different RNA-binding proteins and differential assembly of this class of RNP granules dependent on specific cellular stress conditions.

Moreover, other RNA-binding proteins such as Fused in Sarcoma (FUS) and Transactive Response DNA Binding Protein of 43 KDa (TDP-43) have also been found to associate with stress granules and mediate their assembly. FUS and TDP-43 are multifunctional proteins with roles which include regulating various aspects of RNA metabolism. For example, regulating mRNA transcription, splicing, transport, translation, regulating expression of noncoding RNAs and RNP granule formation. The RNA-binding proteins are predominantly located in the nucleus but in order to execute this effectively, they are constantly shuttled between the nucleus and cytoplasm (MacKenzie et al., 2010; Ling et al., 2013). Interestingly, FUS and TDP-43 are also neurodegenerative disease-associated proteins, and there is a mislocalisation of the proteins to the cytoplasm where they form characteristic pathological inclusions as observed in post mortem brain tissue from a subset of frontotemporal dementia and ALS cases (Neumann et al., 2006; 2009). In addition, the RNA-binding proteins have also been shown to associate with stress granules thus becoming cytoplasmically sequestered (Liu-Yesucevitz et al., 2010; Bentmann et al., 2013). Therefore, FUS and TDP-43 recruitment into stress granules and subsequent nuclear loss of the RNA-binding proteins, in addition to persistence of these RNP granules, may contribute to the progressive intraneuronal protein aggregation, neuronal degeneration and loss characteristic of frontotemporal dementia and ALS.

\subsection{Paraspeckles}

Paraspeckles are RNP granules located in the interchromatin space of mammalian cell nuclei. They are thought to be involved in regulating gene expression through nuclear 
retention of RNA (Fox et al., 2002; 2018; Andersen et al., 2002; Bond and Fox, 2009). As indicated by fluorescence recovery after photobleaching-based experiments, they too are highly dynamic structures which are associated with the cellular stress response (Mao et al., 2011). Unlike transient stress granules, paraspeckles are constitutively expressed in cells, however they do indeed exhibit increased formation under stressful conditions (An et al., 2018). Paraspeckles consist of RNA and RNA-binding protein components. As with stress granules, analyses by electron and super-resolution microscopy have revealed that paraspeckles similarly have a core-shell structure but also contain associated patch regions, together enabling spatial control over the localisation of RNA and RNA-binding proteins (Souquere et al., 2010; Kawaguchi et al., 2015; West et al., 2016). Figure 1b summarises this paraspeckle structure.

Nuclear Enriched Abundant Transcript 1 (NEAT1) is a long non-coding RNA (IncRNA) that is ubiquitous, highly expressed and conserved across mammalian species (An et al., 2018). Knockdown of NEAT1 in cultured cells has been found to result in a loss of paraspeckles illustrating the essential role of the IncRNA in paraspeckle formation maintenance (Clemson et al., 2009; Chen and Carmichael, 2009; Sasaki et al., 2009). The IncRNA has multiple splice variants in humans, of which the two most abundant isoforms are NEAT1_1 (3.7 kb in humans) and the longer transcript NEAT1_2 (22.7 kb in humans) (Hutchinson et al., 2007; Sunwoo et al., 2009; Wilusz et al., 2012). Specifically, the longer NEAT1_2 transcript is required for paraspeckle assembly as it acts as a scaffold to which paraspeckle proteins can then bind, as opposed to NEAT1_1 which, in the presence of NEAT1_2, only enhances paraspeckle assembly (Chen and Carmichael, 2009; Sasaki et al., 2009; Naganuma et al., 2012). Under conditions of stress, NEAT1_2 expression is upregulated, leading to an increased number and size of paraspeckles (Sunwoo et al., 2009; Hirose et al., 2014).

The majority of the paraspeckle proteome consists of RNA-binding proteins which can serve to either bind to the NEAT1_2 transcript and stabilise it, regulate the formation of the two NEAT1 isoforms, or maintain secondary structure of paraspeckles (Lin et al., 2018; Yamazaki et al., 2020). Splicing Factor Proline and Glutamine Rich (SPFQ) and Non-POU Domain Containing Octamer Binding (NONO) are proteins that bind to high-affinity binding sites on NEAT1_2 and thus stabilise it within the paraspeckle core. Multiple NEAT1_2 transcripts can then align to form the spherical structure of paraspeckles (Sunwoo et al., 2009; Sasaki et al., 2009; Lee et al., 2015; Kawaguchi et al., 2015; An et al., 2018.). The frontotemporal dementia- and ALS-associated RNA-binding protein FUS, is recruited to the core, most likely thought by SPFQ and NONO, where it can regulate the secondary structure of paraspeckles. Interestingly, FUS is actually a required protein for paraspeckle assembly, in contrast to the formation of stress granules (Shelkovnikova et al., 2014; An et al., 2019; Yamazaki et al., 2020). TDP-43 however, is recruited to the shell which is suggestive of its non-essential role in the formation of paraspeckles (Hennig et al., 2015; Fox et al., 2018).

\section{Properties of RNA-Binding Proteins}

RNA-binding proteins are a key component of RNP granules. Although they have varied functions related to the regulation of RNA metabolism and gene expression in response to stress, there are common features shared amongst this group of proteins. They are 
intrinsically aggregation-prone proteins, and in general, structurally contain a nuclear localisation signal, nuclear export signal and prion-like low complexity domain which are all crucial to effectively carrying out their functions within cells (Dreyfuss et al., 2002; Lee et al., 2006; Protter and Parker, 2016; Uversky et al., 2017; Banani et al., 2017; Gehring et al., 2017). Recent advances have enabled insights to be gained into the organisation of RNAbinding proteins and assembly into RNP granules. The following subsections describe some interesting properties of RNA-binding proteins.

\subsection{Liquid-Liquid Phase Separation}

Multidisciplinary approaches have demonstrated that RNA-binding proteins mediate the assembly of membraneless organelles, such as stress granules and paraspeckles, via the process of liquid-liquid phase separation (Brangwynne et al., 2009; 2011; Li et al., 2012; Wright and Dyson, 2015; Conicella et al., 2016; Protter and Parker, 2016). This is a process by which there is spontaneous separation of a saturated solution into a dense droplet-like phase and a dilute phase which stably co-exist. In a biological context, RNP granules themselves are considered to be the dense phase, whereas the dilute phase is the surrounding cytoplasm or nucleoplasm (Banani et al., 2017; Shin and Brangwynne, 2017).

In order to understand the properties and dynamics of these granule 'droplets' in real time, research has widely employed the use of techniques such as fluorescence recovery after photobleaching (FRAP) which provides measures on the mobility of droplets and fluorescence recovery rates. An additional approach to investigate droplet properties is to monitor reversibility of the droplets or study the progressive formation of aggregates (Elbaum-Garfinkle, 2019). By employing such techniques in vitro, FUS for example was shown to form droplets by phase separation (Burke et al., 2015), which had fast and complete recovery rates thus indicative of the highly dynamic nature of the RNA-binding protein (Patel et al., 2015). Similarly, in cells TDP-43 has also been shown to undergo phase separation forming droplets of high dynamicity as suggested by the measured recovery rates after photobleaching (Conicella et al., 2016), with the proportion of droplets in cells increasing in a concentration-dependent and time-dependent manner (Gasset-Rosa et al., 2019).

Phase separation involves an initial self-aggregation of the proteins into liquid droplets (Molliex et al., 2015; Lin et al., 2015), and as the concentration of these proteins increases via further recruitment to the RNP granules, the RNA-binding proteins have been shown to reversibly form a hydrogel-like state (Kato et al., 2012). These structures have been found to undergo a liquid-to-solid phase transition into stable, hence not easily reversible, insoluble aggregates (Patel et al., 2015; Murakami et al., 2015; Lim et al., 2016; Gasset-Rosa et al., 2019). Therefore, a key determinant driving phase separation is a change in the concentration of the aggregation-prone RNA-binding proteins. Once a critical concentration is reached, phase separation is believed to spontaneously occur, and as this concentration increases it stimulates more of the RNA-binding protein to become recruited in a cooperative manner (Hyman et al., 2014; Shin and Brangwynne et al., 2017; Gasset-Rosa et al., 2019). 


\subsection{Low Complexity Domains}

The RNA-binding protein low complexity domains are a critical structural component for phase separation (Molliex at al., 2015; Harrison and Shorter, 2017). These domains are intrinsically disordered, enriched in polar amino acids, such as asparagine, glutamine, tyrosine and serine, that often occur in short repetitive sequences (Michelitsch et al., 2000; Alberti et al., 2009). Proteins interact through weak electrostatic forces via their prion-like low complexity domains forming a denser structure than the cytoplasm or nucleoplasm in a concentration-dependent manner (Kato et al., 2012; Han et al., 2012; Mackenzie et al., 2017).

The importance of the prion-like low complexity domains has been elucidated in mutational studies investigating key RNA-binding proteins and RNP granule properties. For example, Mackenzie et al. (2017) investigated the effect of frontotemporal dementia- and ALSassociated mutations in the low complexity domain of TIA 1 on stress granule properties and dynamics. TIA 1 droplets had a reduced mobile fraction by FRAP and were found to be less reversible. In addition, using a live-cell assay they found that despite the mutations not affecting stress granule assembly, disassembly was impaired. Moreover, in addition to looking at wild-type FUS, Patel et al. (2015) also investigated the effect of an ALS-associated mutation in the low complexity domain of FUS, finding that with time, the mutated FUS droplets become less reversible, and resulted in a reduced mobile fraction in FRAP experiments. Furthermore, Johnson et al. (2009) compared TDP-43 protein domains to investigate which regions were vital for in vitro self-aggregation, identifying the C-terminal low complexity domain rather than the $\mathrm{N}$-terminal domain to be critical to the formation of TDP-43 cytoplasmic aggregates. In addition, using a yeast TDP-43 proteinopathy model, they assessed the in vivo effect of ALS-associated mutations in the low complexity domain on TDP-43 aggregate formation. Overall, mutations resulted in an increased formation of TDP43 cytoplasmic aggregates as confirmed by microscopy experiments and sedimentation assays (Johnson et al., 2009). More recently, ALS-associated mutations in the TDP-43 low complexity domain were also found to result in disrupted phase separation of TDP-43 droplets by altering interactions via specific helix-helix contacts in the protein low complexity domain (Conicella et al., 2016). Together, this suggests aggregation through intermolecular interactions via the low complexity domain of RNA-binding proteins is vital for regulating core RNP granule biophysical properties and dynamics.

\subsection{Post-Translational Modifications}

RNA-binding proteins are rich in amino acid residues that are common targets for posttranslational modifications, and such molecular changes have been found to affect the propensity of these proteins to phase separate (Tourrière et al., 2003; Ohn et al., 2008; Rhoads et al., 2018). In addition, stress can stimulate the introduction of post-translational modifications which affect phase separation (Nott et al., 2015; Bah et al., 2016; Su et al., 2016). The post-translational modifications can result in changes to the properties of the low complexity domains of RNA-binding proteins, such as the bulkiness, charge, or charge distribution, thus leading to a directly altered affinity of intermolecular interactions via these domains (Hofweber and Dormann, 2019). As such, this provides a powerful mechanism to enable modulation of phase separation in cells in response to changing environmental conditions. 
Phosphorylation and arginine-methylation are two well-studied examples of posttranslational modifications in the context of RNA-binding proteins (Aumiller and Keating, 2016; Ryan et al., 2018). An overall negative charge is introduced by phosphorylation whereas arginine-methylation changes the charge distribution, hydrophobic properties and increases the bulkiness (Bah et al., 2016). These changes alter the intermolecular interactions between RNA-binding proteins and therefore regulate their ability to undergo phase separation, but the direction of which can be dependent on the protein being modified as well as the modification itself (Kwon et al., 2013; Lin et al., 2017; Gomes and Shorter, 2019).

Phosphorylation is the most common post-translational modification, and unlike arginine methylation, it is rapid and reversible, and a key regulator of many cellular processes (Bah et al., 2016). Depending upon the protein involved, phosphorylation can suppress or enhance phase separation. For example, Monahan et al. (2017) investigated the effect of phosphorylation of FUS on phase separation properties and aggregation of the protein in vitro. Unlike wild-type low complexity domains of FUS, FUS low complexity domains carrying phosphomimetic substitutions showed no phase separation or aggregation in vitro.

Additionally, phosphorylation of FUS was also found to prevent its liquid-to-solid state transition and aggregation formation. Furthermore, they found that, when expressed in cells, FUS with phosphomimetic substitutions showed a reduction in its propensity to aggregate, and hence the cells exhibited reduced toxicity (Monahan et al., 2017). Together, this suggests that phosphorylation of FUS disrupts its phase separation, thereby reducing its aggregation and subsequent toxic effects. Similarly, Wang et al. (2018) introduced a phosphomimetic substitution in TDP-43 finding this change disrupted its phase separation in in vitro experiments. However, they also found that this could be overcome by higher protein concentrations where phase separation was visible, suggestive of a more complex interaction of factors governing the molecular properties and behaviour of RNA-binding proteins such as TDP-43 (Wang et al., 2018). Understanding this interaction is of particular relevance to neurodegeneration given that abnormal phosphorylation of TDP-43 is present at various sites in cases of frontotemporal dementia and ALS (Arai et al., 2006).

In contrast, phosphorylation of the microtubule-associated protein tau, which is implicated in neurodegeneration across various tauopathies (Wang et al., 2016), enhances its phase separation (Ambadipudi et al., 2017; Wegmann et al., 2018). Tau is not typically classified as an RNA-binding protein, however it is thought to be able to bind to TIA 1 enabling it to associate with stress granules and can also bind RNA (Vanderweyde et al., 2012; 2016; Maziuk et al., 2018), highlighting its relevance to be discussed here. Wegmann et al. (2018) compared unphosphorylated-, dephosphorylated- and hyperphosphorylated-tau, and by using imaging-based techniques found that phosphorylation enhanced phase separation of the protein. These findings are aligned with the occurrence of hyperphosphorylated tau present in protein aggregates in the brains of individuals with tauopathies such as frontotemporal dementia (Wang et al., 2016).

Various studies have probed the effect of arginine methylation on phase separation of RNAbinding proteins and RNP granule dynamics. The effect of arginine methylation of G3BP1 on stress granule formation was investigated by Tsai et al. (2016). Using a genetic and biochemical approach they found that increased methylation reduced stress granule 
assembly and that this was reversed by pharmacological inhibition of arginine methyltransferases, or induction of arsenite stress. Similarly, arginine methylation of FUS seems to suppress its phase separation hence maintaining the protein in a dynamic state. Hofweber et al. (2018) compared unmethylated with dimethylated FUS, and found that methylated FUS showed an increased droplet dynamics using FRAP-based experiments, and when introduced into stress granule-positive cells, methylated FUS associated with stress granules at lower levels than unmethylated FUS. In addition, Qamar et al. (2018) found that hypomethylated FUS had a greater propensity to form liquid droplets and that these also exhibited reduced dynamics. In addition the group found condensates of hypomethylated FUS had an increased binding and fluorescence of pFTAA, an amyloidogenic dye, suggesting the presence of hydrogel formation. Furthermore, hypomethylated FUS has been identified in the protein aggregates in cases of frontotemporal dementia (Dormann et al., 2012; Suárez-Calvet et al., 2016), again emphasising the relevance of post-translationally modified RNA-binding proteins to neurodegenerative pathology.

\subsection{Neurodegenerative Disease-Associated Mutations}

Mutational studies have enabled great progress to be made towards understanding phase separation of RNA-binding proteins and RNP granule dynamics. Such mutations in RNAbinding proteins like FUS and TDP-43 are linked to neurodegeneration in frontotemporal dementia and ALS (Mackenzie et al., 2010; King et al., 2012). This may be through affecting either the localisation of the proteins and/or their phase separation behaviour. Therefore, these mutations result in an altered assembly, disassembly and maintenance of RNP granules, subsequently leading to a possible increased propensity to form toxic aggregates over time, which is characteristic of neurodegenerative disease (Guo et al., 2011; Li et al., 2013; Ramaswami et al., 2013; Schwartz et al., 2015).

Under normal conditions, FUS is predominantly a nuclear protein, however causative mutations in neurodegenerative disease are known to affect its localisation as well as its propensity to aggregate (Svetoni et al., 2016). Murakami et al. (2015) investigated the effect of frontotemporal dementia- and ALS-associated mutations in FUS on the reversibility of FUS aggregates both in vitro and in an in vivo model system, finding that the mutations reduced the reversible nature of the FUS aggregates. Further to this, the mutations also resulted in an increased recruitment of additional RNA-binding proteins to the aggregates where they also become sequestered. In addition, An et al. (2019) found that ALS-associated mutations in the low complexity domain of FUS led to the redistribution of FUS to the cytoplasm. Moreover, there was an enhanced formation of paraspeckles through NEAT1 accumulation in cells. However, these paraspeckles were found to be both structurally and functionally compromised. This supports earlier work from the same group in which they found that, in cells expressing high levels of ALS-associated mutant FUS, FUS becomes cytoplasmically located where it forms aggregates that contain key paraspeckle components including NONO (Shelkovnikova et al., 2014).

A common feature to frontotemporal dementia and ALS pathology is TDP-43 aggregation (Neumann et al., 2006; Hasegawa et al., 2008). Interestingly, 97\% of ALS cases exhibit such TDP-43 pathology despite whether they are sporadic or familial in nature, in addition to $45 \%$ of frontotemporal dementia cases (Ling et al., 2013). Shelkovnikova et al. (2018) identified enhanced paraspeckle formation in ALS and investigated the role of TDP-43 dysfunction, as 
a known paraspeckle protein, in driving this effect. Through conducting knockdown and mutational experiments they found specifically the loss of TDP-43 in cells enhanced paraspeckle formation, but only through a significant nuclear loss of TDP-43 was affected paraspeckle assembly observed. To add to this, Conicella et al. (2016) employed a combination of techniques including turbidity assays, imaging and NMR spectroscopy, finding that ALS-associated mutations in TDP-43 disrupted intermolecular interactions via specific contacts in its low complexity domain, thus altering its phase behaviour and promoting transition to aggregates. Additionally, McGurk et al. (2018) also found that ALSassociated mutations in TDP-43 result in impaired phase separation dynamics in vitro. Moreover, further support for a role of TDP-43 in ALS pathogenesis is provided by Fang et al. (2019) who used western blotting and imaging to investigate the effect of prolonged stress on TDP-43 recruitment into stress granules in a human-induced pluripotent stem cellderived motor neuron (iPSC-MN) model system. TDP-43 was shown to robustly accumulate in stress granules in iPSC-MNs, but importantly unlike in control iPSC-MNs, these TDP-43positive stress granules persisted even after withdrawal of stress in iPSC-MNs carrying ALSassociated mutations in TDP-43 (Fang et al., 2019).

Collectively, this supports the idea that disease-associated mutations in RNA-binding proteins such as FUS and TDP-43 alter their intracellular localisation and their properties. As a result leading to the production of less soluble states, and disruption to RNP granule dynamics. Ultimately, this could contribute to pathology in neurodegenerative disease.

\section{Conclusion and Therapeutic Implications}

RNP granules such as stress granules and paraspeckles are essential for biochemical processes to occur efficiently within cells and importantly to maintain function and cell viability under conditions of stress. A key component of such RNP granules are RNA-binding proteins whose intrinsic aggregation-prone properties assist in regulating the assembly, maintenance and disassembly of RNP granules. This regulation can itself be fine-tuned or altered through post-translational modifications to the RNA-binding proteins or by mutations which are often linked to neurodegeneration.

However, many studies investigating the effect of post-translational modifications in RNAbinding proteins have largely studied single modifications in isolation, whereas a more physiologically relevant situation would involve an interaction of many factors which could perhaps include multiple post-translational modifications. The net effect of which on phase separation of RNA-binding proteins and RNP dynamics may differ to those observed in isolation respectively. In addition, the mutations identified, although causal in nature for frontotemporal dementia and ALS, represent only a small proportion of cases, with the vast majority of cases instead being sporadic. Despite this, there are still shared pathological features at the molecular and cellular level between sporadic and familial forms of these neurodegenerative diseases. Therefore, the intrinsic properties and behaviour of wild-type RNA-binding proteins becomes particularly intriguing in these sporadic cases, as it highlights potential mechanisms of pathology via dysregulated RNP granule biology, summarised in Figure 2, which are perhaps exacerbated by neurodegenerative disease-associated mutations. Furthermore, at present it is still unclear whether toxicity in these cases is likely 
triggered by a loss of function by sequestration of key proteins, gain of function through RNP granule assembly or combined mechanisms. Thus, improved tools and technologies will enable a deeper understanding to be gained and great strides to be made in guiding the development of rational and effective therapeutic strategies.

Based on our current understanding, promising therapeutic strategies may involve modulating the biophysical properties of RNP granules, stimulating disassembly of RNP granules or upregulating degradation pathways (Shorter, 2016; 2017; Schoch and Miller, 2017). In order to maintain liquid properties of RNP granules, antisense oligonucleotides could be employed to selectively knockdown proteins involved in aberrant phase transitions either directly or by knocking down their functional partners, such as NEAT1 (Vanderweyde et al., 2016; Becker et al., 2017; Apicco et al., 2018; Boeynaems et al., 2018). Disassembly of RNP granules could be achieved by potentiating the response of molecular chaperones within cells, as these serve to regulate proteostasis by refolding misfolded proteins and hence restoring their cellular function (Vashist et al., 2010; Shorter, 2011; Jackrel et al., 2014; Protter and Parker, 2016). In addition to chaperones, other components of protein quality control systems are impaired by mutations causing neurodegenerative diseases, for example, the autophagolysosomal system (Alberti et al., 2017). Therefore, another possible approach could be to upregulate autophagy (Barmada et al., 2014; Rusmini et al., 2017). It may be that such strategies would be of limited effectiveness individually and instead have greatest impact in combination and perhaps if delivered sequentially at different stages during disease progression.

Overall, although there is a growing body of evidence suggesting a link between biophysical properties and dynamics of RNP granules, protein aggregation, and neurodegenerative disease pathology, future work will need to uncover the underlying molecular mechanisms regulating this process. Ultimately, this will be crucial in order to identify novel targets and discover new avenues for developing effective disease-modifying therapeutics and fulfil the pressing need to combat these devastating diseases.

\section{Acknowledgements}

The Alzheimer's Research UK UCL Drug Discovery Institute receives its core funding from Alzheimer's Research UK (registered charity numbers: 1077089 and SC042474). RB is funded by The Reta Lila Weston Institute of Neurological Studies and The British Neuropathological Society. 


\section{Figures}

A

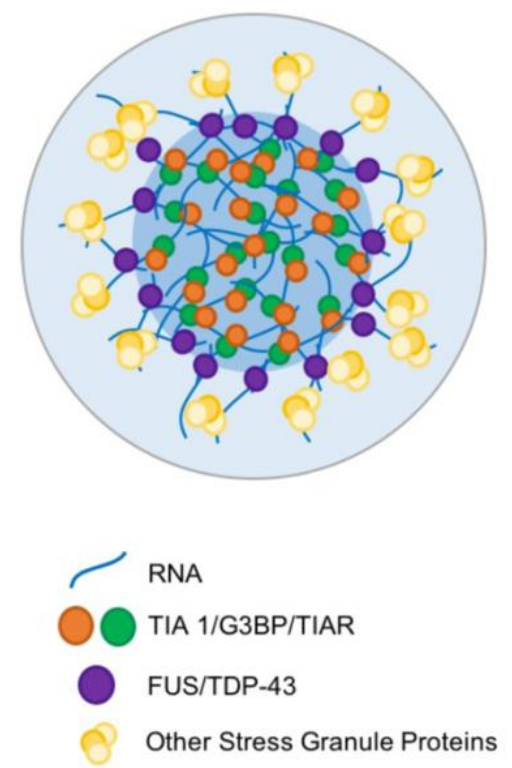

B

Paraspeckle

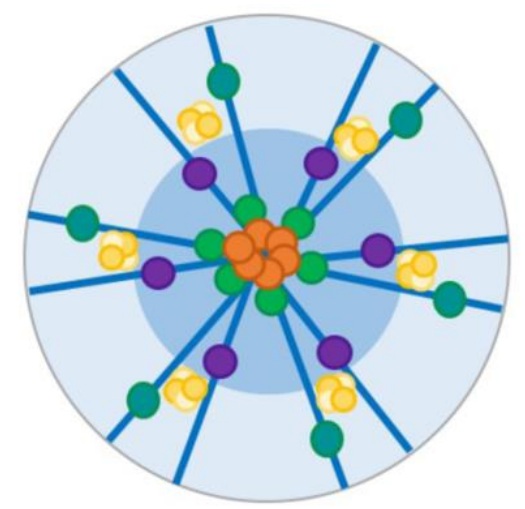

$\checkmark$ neat1

$\bigcirc$ SPFQ and NONO

Paraspeckle Patch Proteins

FUS

TDP-43

\section{Figure 1. Structure of stress granule and paraspeckle RNP granules.}

(A) Schematic structural representation of a cytoplasmic stress granule composed of a core and shell, containing RNA bound with typical stress granule proteins such as TIA 1, G3BP or TIAR, in addition to other frontotemporal dementia- and ALS-associated RNA-binding proteins such as FUS or TDP-43 known to also associate with stress granules, as well as other stress granule-associated proteins. (B) Schematic structural representation of a nuclear paraspeckle composed of a core-shell structure, containing a NEAT1 long noncoding RNA scaffold to which key paraspeckle proteins such as SPFQ and NONO and FUS bind within the paraspeckle core. In addition, TDP-43 is also bound to NEAT1 but is recruited to the shell as a non-essential paraspeckle protein. Associated paraspeckle patch proteins are also recruited to patch regions of a paraspeckle. 
A

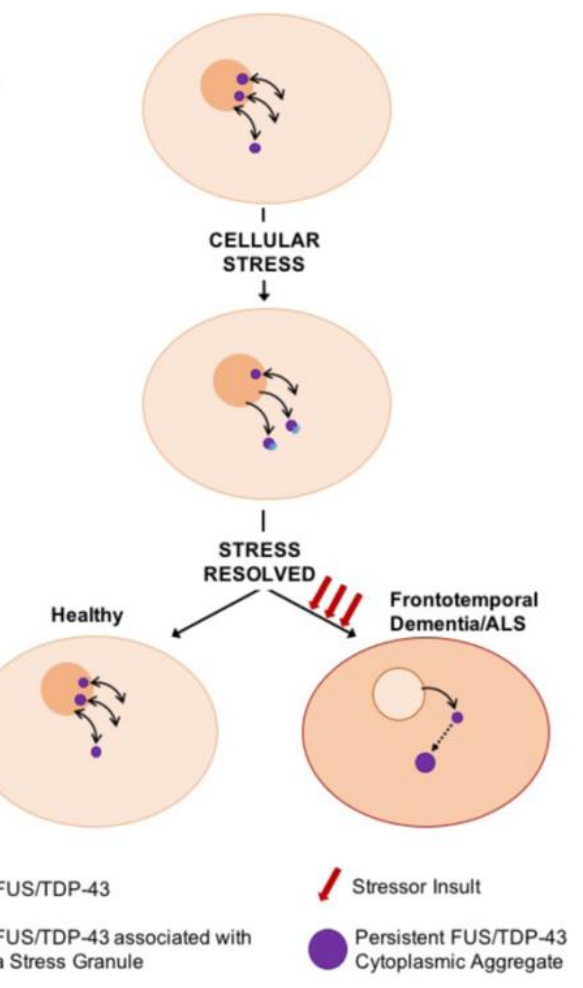

B
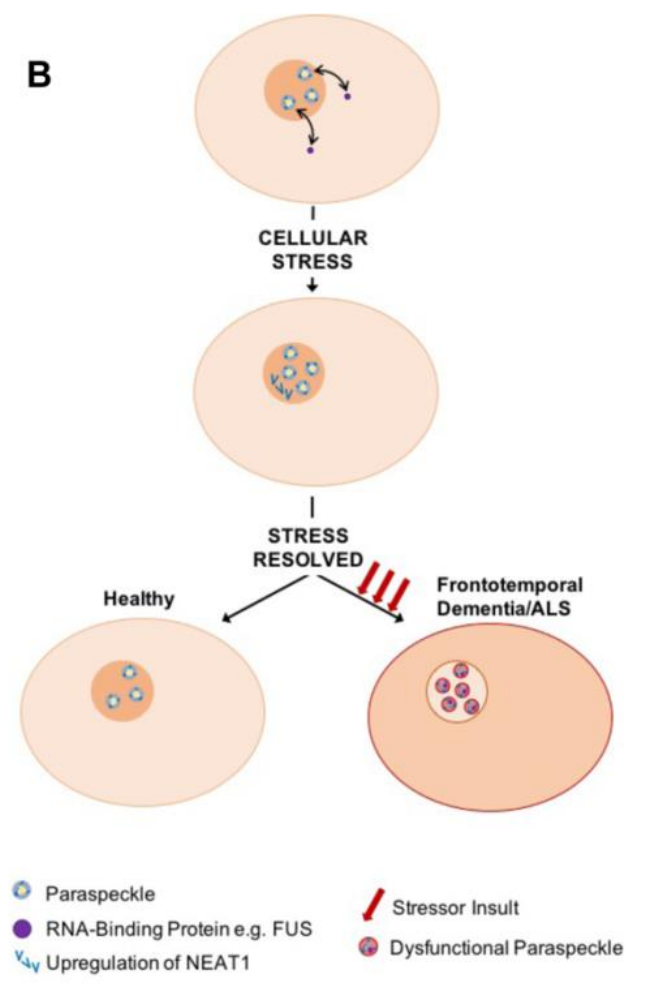

Figure 2. Possible mechanism of frontotemporal dementia and ALS pathogenesis involving RNA-binding proteins and stress granule and paraspeckle RNP granules.

(A) A potential role of stress granule biology in the pathogenesis of frontotemporal dementia and ALS. Under normal conditions RNA-binding proteins such as FUS and TDP-43 are shuttled between the nucleus and cytoplasm of cells. However, upon cellular stress, they mislocalise from the nucleus to the cytoplasm. In the cytoplasm, FUS and TDP-43 associate with stress granules via interaction through their prion-like low complexity domains. This is a protective mechanism which stalls translation initiation enabling the cell to overcome the period of cellular stress by conserving energy and resources. Once the stress is resolved, the RNA-binding proteins return to being shuttled between intracellular compartments in healthy individuals. In contrast, despite the stress being resolved and the disassembly of stress granules, over time there may be multiple successive stressor insults. As a result, the mislocalised aggregated cytoplasmic FUS or TDP-43 may continue to recruit more of the respective RNA-binding proteins in a cooperative manner and via irreversible state changes lead to the formation of persistent FUS-positive or TDP-43-positive cytoplasmic inclusions which could progressively develop into larger aggregates. Although initially this may be cleared efficiently, with age and increasing levels of damage, clearance mechanisms are put under strain and no longer continue to effectively function. Therefore over time, there is an accumulation of damage in cells ultimately resulting in cellular death and neurodegeneration. (B) A possible mechanism of frontotemporal dementia and ALS pathology involving paraspeckle biology. Under normal conditions low numbers of paraspeckles are expressed in the nucleus, and key RNA-binding proteins such as FUS are shuttled between the nucleus and cytoplasm to carry out their various functions, including recruitment to form the nuclear paraspeckles. When exposed to cellular stress, there is an upregulation of the NEAT1 long non-coding RNA transcript, leading to an increase in paraspeckle assembly in the nucleus. Upon overcoming the stressful conditions, NEAT1 levels and hence paraspeckle number return to basal levels. However, further successive 
stressor insults over time, and the associated age-related decline in effective cytoprotective response pathways, may lead to the excessive formation of persistent and dysfunctional paraspeckles which could be actively toxic but also sequester key proteins such as FUS leading to a loss of function. In this way, cells are likely to become increasingly vulnerable to further stress and become dysfunctional and exhibit reduced viability, thus also contributing to neurodegeneration. 


\section{References}

Aguzzi, A., O'Connor, T. (2010). Protein aggregation diseases: pathogenicity and therapeutic perspectives. Nature Reviews Drug Discovery, 9, 237-248. https://doi.org/10.1038/nrd3050

Alberti, S., Halfmann, R., King, O., Kapila, A., Lindquist, S. (2009). A systematic survey identifies prions and illuminates sequence features of prionogenic proteins. Cell, 137(1), 146-158. https://doi.org/10.1016/j.cell.2009.02.044

Alberti, S., Mateju, D., Mediani, L., Carra, S. (2017). Granulostasis: Protein Quality Control of RNP Granules. Frontiers in Molecular Neuroscience, 10, 84.

https://doi.org/10.3389/fnmol.2017.00084

Ambadipudi, S., Biernat, J., Riedel, D., Mandelkow, E., Zweckstetter, M. (2017). Liquid-liquid phase separation of the microtubule-binding repeats of the Alzheimer-related protein Tau. Nature Communications, 8(1), 275. https://doi.org/10.1038/s41467-017-00480-0

An, H., Williams, N. G., Shelkovnikova, T. A. (2018). NEAT1 and paraspeckles in neurodegenerative diseases: A missing Inc found?. Non-coding RNA Research, 3(4), 243252. https://doi.org/10.1016/j.ncrna.2018.11.003

An, H., Skelt, L., Notaro, A., Highley, J. R., Fox, A. H., La Bella, V., Buchman, V. L., Shelkovnikova, T. A. (2019). ALS-linked FUS mutations confer loss and gain of function in the nucleus by promoting excessive formation of dysfunctional paraspeckles. Acta Neuropathologica Communications, 7(1), 7. https://doi.org/10.1186/s40478-019-0658-x

Andersen, J. S., Lyon, C. E., Fox, A. H., Leung, A. K. L., Lam, Y. W., Steen, H., Mann, M., Lamond, A. I. (2002). Directed proteomic analysis of the human nucleolus. Current Biology, 12(1), 1-11. https://doi.org/10.1016/S0960-9822(01)00650-9

Anderson, P., Kedersha, N. (2006). RNA granules. The Journal of Cell Biology, 172(6), 803808. https://doi.org/10.1083/jcb.200512082

Anderson, P., Kedersha, N. (2008). Stress granules: The Tao of RNA Triage. Trends in Biochemical Sciences, 33(3), 141-150, https://doi.org/10.1016/j.tibs.2007.12.003

Apicco, D. J., Ash, P., Maziuk, B., LeBlang, C., Medalla, M., Al Abdullatif, A., Ferragud, A., Botelho, E., Ballance, H. I., Dhawan, U., Boudeau, S., Cruz, A. L., Kashy, D., Wong, A., Goldberg, L. R., Yazdani, N., Zhang, C., Ung, C. Y., Tripodis, Y., Kanaan, N. M., Ikezu, T., Cottone, P., Leszyk, J., Li, H., Luebke, J., Bryant, C. D., Wolozin, B. (2018). Reducing the RNA binding protein TIA1 protects against tau-mediated neurodegeneration in vivo. Nature Neuroscience, 21(1), 72-80. https://doi.org/10.1038/s41593-017-0022-z

Arai, T., Hasegawa, M., Akiyama, H., Ikeda. K., Nonaka, T., Mori, H., Mann, D., Tsuchiya, K., Yoshida, M., Hashizume, Y., Oda T. (2006). TDP-43 is a component of ubiquitin-positive taunegative inclusions in frontotemporal lobar degeneration and amyotrophic lateral sclerosis. 
Biochemical and Biophysical Research Communications, 351(3), 602-611.

https://doi.org/10.1016/j.bbrc.2006.10.093

Aulas, A., Fay, M. M., Lyons, S. M., Achorn, C. A., Kedersha, N., Anderson, P., Ivanov, P. (2017). Stress-specific differences in assembly and composition of stress granules and related foci. The Journal of Cell Science, 130(5), 927-937.

https://doi.org/10.1242/jcs.199240

Aumiller, W.M., Keating, C. D. (2016). Phosphorylation-mediated RNA/peptide complex coacervation as a model for intracellular liquid organelles. Nature Chemistry, 8, 129-137. https://doi.org/10.1038/nchem.2414

Bah, A., Forman-Kay, J. D. (2016). Modulation of Intrinsically Disordered Protein Function by Post-translational Modifications. The Journal of Biological Chemistry, 291(13), 6696-6705. https://doi.org/10.1074/jbc.R115.695056

Banani, S. F., Lee, H. O., Hyman, A. A., Rosen, M. K. (2017). Biomolecular condensates: organizers of cellular biochemistry. Nature Reviews Molecular Cell Biology, 18, 285-298. https://doi.org/10.1038/nrm.2017.7

Barmada, S. J., Serio, A., Arjun, A., Bilican, B., Daub, A., Ando, D. M., Tsvetkov, A., Pleiss, M., Li, X., Peisach, D., Shaw, C., Chandran, S., Finkbeiner, S. (2014). Autophagy induction enhances TDP43 turnover and survival in neuronal ALS models. Nature Chemical Biology, 10(8), 677-685. https://doi.org/10.1038/nchembio.1563

Becker, L. A., Huang, B., Bieri, G., Ma, R., Knowles, D. A., Jafar-Nejad, P., Messing, J., Kim, H. J., Soriano, A., Auburger, G., Pulst, S. M., Taylor, J. P., Rigo, F., Gitler, A. D. (2017). Therapeutic reduction of ataxin-2 extends lifespan and reduces pathology in TDP-43 mice. Nature, 544(7650), 367-371. https://doi.org/10.1038/nature22038

Bentmann, E., Haass, C., Dormann, D. (2013). Stress granules in neurodegeneration lessons learnt from TAR DNA binding protein of $43 \mathrm{kDa}$ and fused in sarcoma. The FEBS Journal, 280(18), 4348- 4370. https://doi.org/10.1111/febs.12287

Boeynaems, S., Alberti, S., Fawzi, N. L., Mittag, T., Polymenidou, M., Rousseau, F., Schymkowitz, J., Shorter, J., Wolozin, B., Van Den Bosch, L., Tompa, P., Fuxreiter, M. (2018). Protein Phase Separation: A New Phase in Cell Biology. Trends in Cell Biology, 28(6), 420435. https://doi.org/10.1016/j.tcb.2018.02.004

Bond, C. S., Fox, A. H. (2009). Paraspeckles: nuclear bodies built on long noncoding RNA. The Journal of Cell Biology; 186(5), 637-644. https://doi.org/10.1083/jcb.200906113

Brangwynne, C. P., Eckmann, C. R., Courson, D. S., Rybarska, A. Hoege, C., Gharakhani, J., Julicher, F., Hymann, A. A. (2009). Germline P granules are liquid droplets that localize by controlled dissolution/condensation. Science, 324(5935), 1729-1732.

https://doi.org/10.1126/science.1172046 
Brangwynne, C. P., Mitchison, T. J., Hyman, A. A. (2011). Active liquid-like behavior of nucleoli determines their size and shape in Xenopus laevis oocytes. Proceedings of the National Academy of Sciences of the United States of America, 108(11), 4334-4339. https://doi.org/10.1073/pnas.1017150108

Buchan, J. R., Parker, R. (2009). Eukaryotic stress granules: the ins and outs of translation. Molecular Cell, 36(6), 932-941. https://doi.org/10.1016/j.molcel.2009.11.020

Buchan, J. R., Yoon, J. H., Parker, R. (2011). Stress-specific composition, assembly and kinetics of stress granules in Saccharomyces cerevisiae. The Journal of Cell Science, 124(2), 228-239. https://doi.org/10.1242/jcs.078444

Burke, K. A., Janke, A. M., Rhine, C. L., Fawzi, N. L. (2015). Residue-by-Residue View of In Vitro FUS Granules that Bind the C-Terminal Domain of RNA Polymerase II. Molecular Cell, 60(2), 231-241. https://doi.org/10.1016/j.molcel.2015.09.006

Chen, L. L., Carmichael, G. G. (2009). Altered nuclear retention of mRNAs containing inverted repeats in human embryonic stem cells: functional role of a nuclear noncoding RNA. Molecular Cell, 35(4), 467-478. https://doi.org/10.1016/j.molcel.2009.06.027

Clemson, C. M., Hutchinson, J. N., Sara, S. A., Ensminger, A. W., Fox, A. H., Chess, A., Lawrence, J. B. (2009). An architectural role for a nuclear noncoding RNA: NEAT1 RNA is essential for the structure of paraspeckles. Molecular Cell, 33(6), 717-726. https://doi.org/10.1016/j.molcel.2009.01.026

Conicella, A. E., Zerze, G. H., Mittal, J., Fawzi, N. L. (2016). ALS Mutations Disrupt Phase Separation Mediated by $\alpha$-Helical Structure in the TDP-43 Low-Complexity C-Terminal Domain. Structure (London, England : 1993), 24(9), 1537-1549.

https://doi.org/10.1016/j.str.2016.07.007

Dormann, D., Madl, T., Valori, C. F., Bentmann, E., Tahirovic, S., Abou-Ajram, C., Kremmer, E., Ansorge, O., Mackenzie, I. R., Neumann, M., Haass, C. (2012). Arginine methylation next to the PY-NLS modulates Transportin binding and nuclear import of FUS. The EMBO Journal, 31(22), 4258-4275. https://doi.org/10.1038/emboj.2012.261

Dreyfuss, G., Kim, V. N., Kataoka, N. (2002). Messenger-RNA-binding proteins and the messages they carry. Nature Reviews Molecular Cell Biology, 3(3), 195-205. https://doi.org/10.1038/nrm760

Elbaum-Garfinkle S. (2019). Matter over mind: Liquid phase separation and neurodegeneration. The Journal of Biological Chemistry, 294(18), 7160-7168. https://doi.org/10.1074/jbc.REV118.001188

Erkkinen, M. G., Kim, M. O., Geschwind, M. D. (2018). Clinical Neurology and Epidemiology of the Major Neurodegenerative Diseases. Cold Spring Harbor Perspectives in Biology, 10(4), a033118. https://doi.org/10.1101/cshperspect.a033118 
Fang, M. Y., Markmiller, S., Vu, A. Q., Javaherian, A., Dowdle, W. E., Jolivet, P., Bushway, P. J., Castello, N. A., Baral, A., Chan, M. Y., Linsley, J. W., Linsley, D., Mercola, M., Finkbeiner, S., Lecuyer, E., Lewcock, J. W., Yeo, G. W. (2019). Small-Molecule Modulation of TDP-43 Recruitment to Stress Granules Prevents Persistent TDP-43 Accumulation in ALS/FTD. Neuron, 103(5), 802-819.e11. https://doi.org/10.1016/j.neuron.2019.05.048

Formicola N., Vijayakumar J., Besse F. (2019). Neuronal ribonucleoprotein granules: Dynamic sensors of localized signals. Traffic, 20(9), 639-649. https://doi.org/10.1111/tra.12672

Fox, A. H., Lam, Y. W., Leung, A. K., Lyon, C. E., Andersen, J., Mann, M., Lamond, A. I. (2002). Paraspeckles: a novel nuclear domain. Current Biology, 12, 13-25. https://doi.org/10.1016/S0960-9822(01)00632-7

Fox, A. H., Nakagawa, S., Hirose, T., Bond, C. S. (2018). Paraspeckles: Where Long Noncoding RNA Meets Phase Separation. Trends in Biochemical Sciences, 43, 124-135. https://doi.org/ 10.1016/j.tibs.2017.12.001

Gan, L., Cookson, M. R., Petrucelli, L., La Spada, A. R. (2018). Converging pathways in neurodegeneration, from genetics to mechanisms. Nature Neuroscience, 21(10), 13001309. https://doi.org/10.1038/s41593-018-0237-7

Gao, F. B., Almeida, S., Lopez-Gonzalez, R. (2017). Dysregulated molecular pathways in amyotrophic lateral sclerosis-frontotemporal dementia spectrum disorder. The EMBO Journal, 36(20), 2931-2950. https://doi.org/10.15252/embj.201797568

Gasset-Rosa, F., Lu, S., Yu, H., Chen, C., Melamed, Z., Guo, L., Shorter, J., Da Cruz, S., and Cleveland, D. W. (2019). Cytoplasmic TDP-43 De-mixing Independent of Stress Granules Drives Inhibition of Nuclear Import, Loss of Nuclear TDP-43, and Cell Death. Neuron, 102(2), 339-357.e7. https://doi.org/10.1016/j.neuron.2019.02.038

Gehring, N. H., Wahle, E., Fischer, U. (2017). Deciphering the mRNP code: RNA-bound determinants of post-transcriptional gene regulation. Trends in Biochemical Science, 42, 369-382. https://doi.org/10.1016/j.tibs.2017.02.004

Gomes, E., Shorter, J. (2019). The molecular language of membraneless organelles. The Journal of Biological Chemistry, 294(18), 7115-7127.

https://doi.org/10.1074/jbc.TM118.001192

Guo, W., Chen, Y., Zhou, X., Kar, A., Ray, P., Chen, X., Rao, E. J., Yang, M., Ye, H., Zhu, L., Liu, J., Xu, M., Yang, Y., Wang, C., Zhang, D., Bigio, E. H., Mesulam, M., Shen, Y., Xu, Q., Fushimi, K., Wu, J. Y. (2011). An ALS-associated mutation affecting TDP-43 enhances protein aggregation, fibril formation and neurotoxicity. Nature Structural \& Molecular Biology, 18(7), 822-830. https://doi.org/10.1038/nsmb.2053

Han, T. W., Kato, M., Xie, S., Wu, L. C., Mirzaei, H., Pei, J., Chen, M., Xie, Y., Allen, J., Xiao, G., McKnight, S. L. (2012). Cell-free formation of RNA granules: bound RNAs identify features 
and components of cellular assemblies. Cell, 149(4), $768-779$.

https://doi.org/10.1016/j.cell.2012.04.016

Harrison, A. F., Shorter, J. (2017). RNA-binding proteins with prion-like domains in health and disease. The Biochemical Journal, 474(8), 1417-1438.

https://doi.org/10.1042/BCJ20160499

Hasegawa, M., Arai, T., Nonaka, T., Kametani, F., Yoshida, M., Hashizume, Y., Beach, T. G., Buratti, E., Baralle, F., Morita, M., Nakano, I., Oda, T., Tsuchiya, K., Akiyama, H. (2008). Phosphorylated TDP-43 in frontotemporal lobar degeneration and amyotrophic lateral sclerosis. Annals of Neurology, 64(1), 60-70. https://doi.org/10.1002/ana.21425

Hennig, S., Kong, G., Mannen, T., Sadowska, A., Kobelke, S., Blythe, A., Knott, G. J., Iyer, K. S., Ho, D., Newcombe, E. A., Hosoki, K., Goshima, N., Kawaguchi, T., Hatters, D., TrinkleMulcahy, L., Hirose, T., Bond, C. S., Fox, A. H. (2015). Prion-like domains in RNA binding proteins are essential for building subnuclear paraspeckles. The Journal of Cell Biology, 210(4), 529-539. https://doi.org/10.1083/jcb.201504117

Hirose, T., Virnicchi, G., Tanigawa, A., Naganuma, T., Li, R., Kimura, H., Yokoi, T., Nakagawa, S., Bénard, M., Fox, A. H., Pierron, G. (2014). NEAT1 long noncoding RNA regulates transcription via protein sequestration within subnuclear bodies. Molecular Biology of the Cell, 25(1), 169-183. https://doi.org/10.1091/mbc.E13-09-0558

Hofweber, M., Hutten, S., Bourgeois, B., Spreitzer, E., Niedner-Boblenz, A., Schifferer, M., Ruepp, M. D., Simons, M., Niessing, D., Madl, T., Dormann, D. (2018). Phase separation of FUS is suppressed by its nuclear import receptor and arginine methylation. Cell, 173, 706719.e13. https://doi.org/10.1016/j.cell.2018.03.004

Hofweber, M., Dormann, D. (2019). Friend or foe-Post-translational modifications as regulators of phase separation and RNP granule dynamics. The Journal of Biological Chemistry, 294(18), 7137-7150. https://doi.org/10.1074/jbc.TM118.001189

Hutchinson, J. N., Ensminger, A. W., Clemson, C. M., Lynch, C. R., Lawrence, J. B., Chess, A. (2007). A screen for nuclear transcripts identifies two linked noncoding RNAs associated with SC35 splicing domains. BMC Genomics, 8, 39. https://doi.org/10.1186/1471-2164-8-39

Hyman, A. A., Weber, C. A., Jülicher, F. (2014). Liquid-liquid phase separation in biology. Annual Review of Cell Developmental Biology, 30, 39-58. https://doi.org/10.1146/ annurevcellbio-100913-013325

Jackrel, M. E., DeSantis, M. E., Martinez, B. A., Castellano, L. M., Stewart, R. M., Caldwell, K. A., Caldwell, G. A., Shorter, J. (2014). Potentiated Hsp104 variants antagonize diverse proteotoxic misfolding events. Cell, 156(1-2), 170-182.

https://doi.org/10.1016/j.cell.2013.11.047 
Jain, S., Wheeler, J. R., Walters, R. W., Agrawal, A., Barsic, A., Parker, R. (2016). ATPaseModulated Stress Granules Contain a Diverse Proteome and Substructure. Cell, 164(3), 487498. https://doi.org/10.1016/j.cell.2015.12.038

Johnson, B. S., Snead, D., Lee, J. J., McCaffery, J. M., Shorter, J., Gitler, A. D. (2009). TDP-43 is intrinsically aggregation-prone, and amyotrophic lateral sclerosis-linked mutations accelerate aggregation and increase toxicity. The Journal of Biological Chemistry, 284(30), 20329-20339. https://doi.org/10.1074/jbc.M109.010264

Kato, M., Han, T. W., Xie, S., Shi, K., Du, X., Wu, L. C., Mirzaei, H., Goldsmith, E. J., Longgood, J., Pei, J., Grishin, N. V., Frantz, D. E., Schneider, J. W., Chen, S., Li, L., Sawaya, M. R., Eisenberg, D., Tycko, R., McKnight, S. L. (2012). Cell-free formation of RNA granules: low complexity sequence domains form dynamic fibers within hydrogels. Cell, 149(4), 753-767. https://doi.org/10.1016/j.cell.2012.04.017

Kawaguchi, T., Tanigawa, A., Naganuma, T., Ohkawa, Y., Souquere, S., Pierron, G., Hirose, T. (2015). SWI/SNF chromatin-remodeling complexes function in noncoding RNA-dependent assembly of nuclear bodies. Proceedings of the National Academy of Sciences of the United States of America, 112(14), 4304-4309. https://doi.org/10.1073/pnas.1423819112

Kedersha, N. L., Gupta, M., Li, W., Miller, I., Anderson, P. (1999). RNA-binding proteins TIA-1 and TIAR link the phosphorylation of elF-2 alpha to the assembly of mammalian stress granules. The Journal of Cell Biology, 147(7), 1431-1442.

https://doi.org/10.1083/jcb.147.7.1431

Kedersha, N., Panas, M. D., Achorn, C. A., Lyons, S., Tisdale, S., Hickman, T., Thomas, M., Lieberman, J., Mclnerney, G. M., Ivanov, P., Anderson, P. (2016). G3BP-Caprin1-USP10 complexes mediate stress granule condensation and associate with $40 \mathrm{~S}$ subunits. The Journal of Cell Biology, 212(7), 845-860. https://doi.org/10.1083/jcb.201508028

Khong, A., Matheny, T., Jain, S., Mitchell, S. F., Wheeler, J. R., Parker, R. (2017). The Stress Granule Transcriptome Reveals Principles of mRNA Accumulation in Stress Granules. Molecular Cell, 68(4), 808-820.e5. https://doi.org/10.1016/j.molcel.2017.10.015

King, O. D., Gitler, A. D., Shorter, J. (2012). The tip of the iceberg: RNA-binding proteins with prion-like domains in neurodegenerative disease. Brain Research, 1462, 61-80.

https://doi.org/10.1016/j.brainres.2012.01.016

Kwon, I., Kato, M., Xiang, S., Wu, L., Theodoropoulos, P., Mirzaei, H., Han, T., Xie, S., Corden, J. L., McKnight, S. L. (2013). Phosphorylation-regulated binding of RNA polymerase II to fibrous polymers of low-complexity domains. Cell, 155(5), 1049-1060.

https://doi.org/10.1016/j.cell.2013.10.033

Lee, B. J., Cansizoglu, A. E., Süel, K. E., Louis, T. H., Zhang, Z., Chook, Y. M. (2006). Rules for nuclear localization sequence recognition by karyopherin beta 2. Cell, 126(3), 543-558. https://doi.org/10.1016/j.cell.2006.05.049 
Lee, M., Sadowska, A., Bekere, I., Ho, D., Gully, B. S., Lu, Y., Iyer, K. S., Trewhella, J., Fox, A. H., Bond, C. S. (2015). The structure of human SFPQ reveals a coiled-coil mediated polymer essential for functional aggregation in gene regulation. Nucleic Acids Research, 43(7), 38263840. https://doi.org/10.1093/nar/gkv156

Li, P., Banjade, S., Cheng, H. C., Kim, S., Chen, B., Guo, L., Llaguno, M., Hollingsworth, J. V., King, D. S., Banani, S. F., Russo, P. S., Jiang, Q. X., Nixon, B. T., Rosen, M. K. (2012). Phase transitions in the assembly of multivalent signalling proteins. Nature, 483(7389), 336-340. https://doi.org/10.1038/nature10879

Li, Y. R., King, O. D., Shorter, J., Gitler, A. D. (2013). Stress granules as crucibles of ALS pathogenesis. The Journal of Cell Biology, 201(3), 361-372.

https://doi.org/10.1083/jcb.201302044

Lim, L., Wei, Y., Lu, Y., Song, J. (2016). ALS-Causing Mutations Significantly Perturb the SelfAssembly and Interaction with Nucleic Acid of the Intrinsically Disordered Prion-Like Domain of TDP-43. PLOS Biology, 14(1): e1002338. https://doi.org/10.1371/journal.pbio.1002338

Lin, Y., Protter, D. S., Rosen, M. K., Parker, R. (2015). Formation and Maturation of PhaseSeparated Liquid Droplets by RNA-Binding Proteins. Molecular Cell, 60(2), 208-219. https://doi.org/10.1016/j.molcel.2015.08.018

Lin, Y., Currie, S. L., Rosen, M. K. (2017). Intrinsically disordered sequences enable modulation of protein phase separation through distributed tyrosine motifs. The Journal of Biological Chemistry, 292(46), 19110-19120. https://doi.org/10.1074/jbc.M117.800466

Lin, Y., Schmidt, B. F., Bruchez, M. P., McManus, C. J. (2018). Structural analyses of NEAT1 IncRNAs suggest long-range RNA interactions that may contribute to paraspeckle architecture. Nucleic Acids Research, 46(7), 3742-3752. https://doi.org/10.1093/nar/gky046

Ling, S. C., Polymenidou, M., Cleveland, D. W. (2013). Converging mechanisms in ALS and FTD: disrupted RNA and protein homeostasis. Neuron, 79(3), 416-438.

https://doi.org/10.1016/j.neuron.2013.07.033

Liu-Yesucevitz, L., Bilgutay, A., Zhang, Y. J., Vanderweyde, T., Citro, A., Mehta, T., Zaarur, N., McKee, A., Bowser, R., Sherman, M., Petrucelli, L., Wolozin, B. (2010). Tar DNA binding protein-43 (TDP-43) associates with stress granules: analysis of cultured cells and pathological brain tissue. Plos One, 5(10), e13250.

https://doi.org/10.1371/journal.pone.0013250

Mackenzie, I. R., Rademakers, R., Neumann, M. (2010). TDP-43 and FUS in amyotrophic lateral sclerosis and frontotemporal dementia. The Lancet Neurology, 9(10), 955-1007. https://doi.org/10.1016/S1474-4422(10)70195-2

Mackenzie, I. R., Nicholson, A. M., Sarkar, M., Messing, J., Purice, M. D., Pottier, C., Annu, K., Baker, M., Perkerson, R. B., Kurti, A., Matchett, B. J., Mittag, T., Temirov, J., Hsiung, G. R., Krieger, C., Murray, M. E., Kato, M., Fryer, J. D., Petrucelli, L., Zinman, L., Weintraub, S., 
Mesulam, M., Keith, J., Zivkovic, S. A., Hirsch-Reinshagen, V., Roos, R. P., Zuchner, S., GraffRadford, N. R., Petersen, R. C., Caselli, R. J., Wszolek, Z. K., Finger, E., Lippa, C., Lacomis, D., Stewart, H., Dickson, D. W., Kim, H, J., Rogaeva, E., Bigio, E., Boylan, K. B., Taylor, J. P., Rademakers, R. (2017). TIA1 Mutations in Amyotrophic Lateral Sclerosis and Frontotemporal Dementia Promote Phase Separation and Alter Stress Granule Dynamics. Neuron, 95(4), 808-816.e9. https://doi.org/10.1016/j.neuron.2017.07.025

Mao, Y. S., Sunwoo, H., Zhang, B., Spector, D. L. (2011). Direct visualization of the cotranscriptional assembly of a nuclear body by noncoding RNAs. Nature Cell Biology, 13(1), 95-101. https://doi.org/10.1038/ncb2140

Markmiller, S., Soltanieh, S., Server, K. L., Mak, R., Jin, W., Fang, M. Y., Luo, E. C., Krach, F., Yang, D., Sen, A., Fulzele, A., Wozniak, J. M., Gonzalez, D. J., Kankel, M. W., Gao, F. B., Bennett, E. J., Lécuyer, E., Yeo, G. W. (2018). Context-Dependent and Disease-Specific Diversity in Protein Interactions within Stress Granules. Cell, 172(3), 590-604.e13. https://doi.org/10.1016/j.cell.2017.12.032

Maziuk, B. F., Apicco, D. J., Cruz, A. L., Jiang, L., Ash, P., da Rocha, E. L., Zhang, C., Yu, W. H., Leszyk, J., Abisambra, J. F., Li, H., Wolozin, B. (2018). RNA binding proteins co-localize with small tau inclusions in tauopathy. Acta Neuropathologica Communications, 6(1), 71. https://doi.org/10.1186/s40478-018-0574-5

McGurk, L., Gomes, E., Guo, L., Mojsilovic-Petrovic, J., Tran, V., Kalb, R. G., Shorter, J., Bonini, N. M. (2018). Poly(ADP-Ribose) Prevents Pathological Phase Separation of TDP-43 by Promoting Liquid Demixing and Stress Granule Localization. Molecular Cell, 71(5), 703717.e9. https://doi.org/10.1016/j.molcel.2018.07.002

Michelitsch, M. D., Weissman, J. S. (2000). A census of glutamine/asparagine-rich regions: implications for their conserved function and the prediction of novel prions. Proceedings of the National Academy of Sciences of the United States of America, 97(22), 11910-11915. https://doi.org/10.1073/pnas.97.22.11910

Mokas, S., Mills, J. R., Garreau, C., Fournier, M. J., Robert, F., Arya, P., Kaufman, R. J., Pelletier, J., Mazroui, R. (2009). Uncoupling stress granule assembly and translation initiation inhibition. Molecular Biology of the Cell, 20(11), 2673-2683. https://doi.org/10.1091/mbc.e08-10-1061

Molliex, A., Temirov, J., Lee, J., Coughlin, M., Kanagaraj, A. P., Kim, H. J., Mittag, T., Taylor, J. P. (2015). Phase separation by low complexity domains promotes stress granule assembly and drives pathological fibrillization. Cell, 163(1), 123-133.

https://doi.org/10.1016/j.cell.2015.09.015

Monahan, Z., Ryan, V. H., Janke, A. M., Burke, K. A., Rhoads, S. N., Zerze, G. H., O'Meally, R., Dignon, G. L., Conicella, A. E., Zheng, W., Best, R. B., Cole, R. N., Mittal, J., Shewmaker, F., Fawzi, N. L. (2017). Phosphorylation of the FUS low-complexity domain disrupts phase 
separation, aggregation, and toxicity. The EMBO Journal, 36(20), 2951-2967.

https://doi.org/10.15252/embj.201696394

Murakami, T., Qamar, S., Lin, J. Q., Schierle, G. S., Rees, E., Miyashita, A., Costa, A. R., Dodd, R. B., Chan, F. T., Michel, C. H., Kronenberg-Versteeg, D., Li, Y., Yang, S. P., Wakutani, Y., Meadows, W., Ferry, R. R., Dong, L., Tartaglia, G. G., Favrin, G., Lin, W. L., Dickson, D. W., Zhem, M., Ron, D., Schmitt-Ulms, G., Fraser, P. E., Schneider, N. A., Holt, C., Vendruscolo, M., Kaminski, C. F., St George-Hyslop, P. (2015). ALS/FTD Mutation-Induced Phase Transition of FUS Liquid Droplets and Reversible Hydrogels into Irreversible Hydrogels Impairs RNP Granule Function. Neuron, 88(4), 678-690. https://doi.org/10.1016/j.neuron.2015.10.030

Naganuma, T., Nakagawa, S., Tanigawa, A., Sasaki, Y. F., Goshima, N., Hirose, T. (2012). Alternative 3 '-end processing of long noncoding RNA initiates construction of nuclear paraspeckles. The EMBO Journal, 31(20), 4020-4034.

https://doi.org/10.1038/emboj.2012.251

Neumann, M., Sampathu, D. M., Kwong, L. K., Truax, A. C., Micsenyi, M. C., Chou, T. T., Bruce, J., Schuck, T., Grossman, M., Clark, C. M., McCluskey, L. F., Miller, B. L., Masliah, E., MacKenzie, I. R., Feldman, H., Kretzschmar, H. A., Trojanowski, J. Q., Lee, V. M. (2006). Ubiquinated TDP-43 in frontotemporal lobar degeneration and amyotrophic lateral sclerosis Science, 314(5796), 130-133. https://doi.org/10.1126/science.1134108

Neumann, M., Rademakers, R., Roeber, S., Baker, M., Kretzschmar, H. A., Mackenzie, I. R. (2009). A new subtype of frontotemporal lobar degeneration with FUS pathology. Brain: A Journal of Neurology, 132(11), 2922-2931. https://doi.org/10.1093/brain/awp214

Nott, T. J., Petsalaki, E., Farber, P., Jervis, D., Fussner, E., Plochowietz, A., Craggs, T. D., Bazett-Jones, D. P., Pawson, T., Forman-Kay, J. D., Baldwin, A. J. (2015). Phase transition of a disordered nuage protein generates environmentally responsive membraneless organelles. Molecular Cell, 57(5), 936-947. https://doi.org/10.1016/j.molcel.2015.01.013

Ohn, T., Kedersha, N., Hickman, T., Tisdale, S., Anderson, P. (2008). A functional RNAi screen links O-GIcNAc modification of ribosomal proteins to stress granule and processing body assembly. Nature Cell Biology, 10(10), 1224-1231. https://doi.org/10.1038/ncb1783

Patel, A., Lee, H. O., Jawerth, L., Maharana, S., Jahnel, M., Hein, M. Y., Stoynov, S., Mahamid, J., Saha, S., Franzmann, T. M., Pozniakovski, A., Poser, I., Maghelli, N., Royer, L. A., Weigert, M., Myers, E. W., Grill, S., Drechsel, D., Hyman, A. A., Alberti, S. (2015). A liquid-to-solid phase transition of the ALS protein FUS accelerated by disease mutation. Cell, 162(5) 1066 1077. https://doi.org/10.1016/j.cell.2015.07.047

Protter, D., Parker, R. (2016). Principles and Properties of Stress Granules. Trends in Cell Biology, 26(9), 668-679. https://doi.org/10.1016/j.tcb.2016.05.004

Qamar, S., Wang, G., Randle, S. J., Ruggeri, F. S., Varela, J. A., Lin, J. Q., Phillips, E. C., Miyashita, A., Williams, D., Ströhl, F., Meadows, W., Ferry, R., Dardov, V. J., Tartaglia, G. G., Farrer, L. A., Kaminski Schierle, G. S., Kaminski, C. F., Holt, C. E., Fraser, P. E., Schmitt-Ulms, 
G., Klenerman, D., Knowles, T., Vendruscolo, M., St George-Hyslop, P. (2018). FUS Phase Separation Is Modulated by a Molecular Chaperone and Methylation of Arginine Cation- $\pi$ Interactions. Cell, 173(3), 720-734.e15. https://doi.org/10.1016/j.cell.2018.03.056

Ramaswami, M., Taylor, J. P., Parker, R. (2013). Altered ribostasis: RNA-protein granules in degenerative disorders. Cell, 154(4), 727-736. https://doi.org/10.1016/j.cell.2013.07.038

Rhoads, S. N., Monahan, Z. T., Yee, D. S., Shewmaker, F. P. (2018). The Role of PostTranslational Modifications on Prion-Like Aggregation and Liquid-Phase Separation of FUS. International Journal of Molecular Sciences, 19(3), 886.

https://doi.org/10.3390/ijms19030886

Rusmini, P., Cristofani, R., Galbiati, M., Cicardi, M. E., Meroni, M., Ferrari, V., Vezzoli, G., Tedesco, B., Messi, E., Piccolella, M., Carra, S., Crippa, V., Poletti, A. (2017). The Role of the Heat Shock Protein B8 (HSPB8) in Motoneuron Diseases. Frontiers in Molecular Neuroscience, 10, 176. https://doi.org/10.3389/fnmol.2017.00176

Ryan, V. H., Dignon, G. L., Zerze, G. H., Chabata, C. V., Silva, R., Conicella, A. E., Amaya, J., Burke, K. A., Mittal, J., Fawzi, N. L. (2018). Mechanistic View of hnRNPA2 Low-Complexity Domain Structure, Interactions, and Phase Separation Altered by Mutation and Arginine Methylation. Molecular Cell, 69(3), 465-479.e7.

https://doi.org/10.1016/j.molcel.2017.12.022

Sasaki, Y. T., Ideue, T., Sano, M., Mituyama, T., Hirose, T. (2009). MENepsilon/beta noncoding RNAs are essential for structural integrity of nuclear paraspeckles. Proceedings of the National Academy of Sciences of the United States of America, 106(8), 2525-2530. https://doi.org/10.1073/pnas.0807899106

Schoch, K. M., Miller, T. M. (2017). Antisense Oligonucleotides: Translation from Mouse Models to Human Neurodegenerative Diseases. Neuron, 94(6), 1056-1070. https://doi.org/10.1016/j.neuron.2017.04.010

Schwartz, J. C., Cech, T. R., Parker, R. R. (2015). Biochemical properties and biological functions of FET proteins. Annual Review of Biochemistry, 84, 355-379. https://doi.org/10.1146/annurev-biochem-060614-034325

Shelkovnikova, T. A., Robinson, H. K., Troakes, C, Ninkina, N., Buchman, V. L. (2014). Compromised paraspeckle formation as a pathogenic factor in FUSopathies. Human Molecular Genetics, 23(9), 2298-2312. https://doi.org/10.1093/hmg/ddt622

Shelkovnikova, T. A., Kukharsky, M. S., An, H., Dimasi, P., Alexeeva, S., Shabir, O., Heath, P. R., Buchman, V. L. (2018). Protective paraspeckle hyper-assembly downstream of TDP-43 loss of function in amyotrophic lateral sclerosis. Molecular Neurodegeneration, 13(1), 30. https://doi.org/10.1186/s13024-018-0263-7

Shin, Y., Brangwynne, C. P. (2017). Liquid phase condensation in cell physiology and disease. Science, 357(eaaf4382). https://doi.org/10.1126/science.aaf4382 
Shorter J. (2011). The mammalian disaggregase machinery: Hsp110 synergizes with Hsp70 and $\mathrm{Hsp} 40$ to catalyze protein disaggregation and reactivation in a cell-free system. PloS One, 6(10), e26319. https://doi.org/10.1371/journal.pone.0026319

Shorter J. (2016). Engineering therapeutic protein disaggregases. Molecular Biology of the Cell, 27(10), 1556-1560. https://doi.org/10.1091/mbc.E15-10-0693

Shorter J. (2017). Designer protein disaggregases to counter neurodegenerative disease. Current Opinion in Genetics \& Development, 44, 1-8.

https://doi.org/10.1016/j.gde.2017.01.008

Souquere, S., Mollet, S., Kress, M., Dautry, F., Pierron, G., Weil, D. (2009). Unravelling the ultrastructure of stress granules and associated P-bodies in human cells. The Journal of Cell Science, 122(20), 3619-3626. https://doi.org/10.1242/jcs.054437

Souquere, S., Beauclair, G., Harper, F., Fox, A., Pierron, G. (2010). Highly ordered spatial organization of the structural long noncoding NEAT1 RNAs within paraspeckle nuclear bodies. Molecular Biology of the Cell, 21(22), 4020-4027. https://doi.org/10.1091/mbc.E1008-0690

Su, X., Ditlev, J. A., Hui, E., Xing, W., Banjade, S., Okrut, J., King, D. S., Taunton, J., Rosen, M. K., Vale, R. D. (2016). Phase separation of signaling molecules promotes T cell receptor signal transduction. Science (New York, N.Y.), 352(6285), 595-599.

https://doi.org/10.1126/science.aad9964

Suárez-Calvet, M., Neumann, M., Arzberger, T., Abou-Ajram, C., Funk, E., Hartmann, H., Edbauer, D., Kremmer, E., Göbl, C., Resch, M., Bourgeois, B., Madl, T., Reber, S., Jutzi, D., Ruepp, M. D., Mackenzie, I. R., Ansorge, O., Dormann, D., Haass, C. (2016). Monomethylated and unmethylated FUS exhibit increased binding to transportin and distinguish FTLD-FUS from ALS-FUS. Acta Neuropathoogica, 131(4), 587-604. https://doi.org/10.1007/s00401016-1544-2

Sunwoo, H., Dinger, M. E., Wilusz, J. E., Amaral, P. P., Mattick, J. S., Spector, D. L. (2009). MEN epsilon/beta nuclear-retained non-coding RNAs are up-regulated upon muscle differentiation and are essential components of paraspeckles. Genome Research, 19(3), 347-359. https://doi.org/10.1101/gr.087775.108

Svetoni, F., Frisone, P., Paronetto, M. P. (2016). Role of FET proteins in neurodegenerative disorders. RNA Biology, 13(11), 1089-1102.

https://doi.org/10.1080/15476286.2016.1211225

Tourrière, H., Chebli, K., Zekri, L., Courselaud, B., Blanchard, J. M., Bertrand, E., Tazi, J. (2003). The RasGAP-associated endoribonuclease G3BP assembles stress granules. The Journal of Cell Biology, 160(6), 823-831. https://doi.org/10.1083/jcb.200212128 
Tsai, W. C., Gayatri, S., Reineke, L. C., Sbardella, G., Bedford, M. T., Lloyd, R. E. (2016). Arginine Demethylation of G3BP1 Promotes Stress Granule Assembly. The Journal of Biological Chemistry, 291(43), 22671-22685. https://doi.org/10.1074/jbc.M116.739573

Uversky, V. N. (2017). Intrinsically disordered proteins in overcrowded milieu: membraneless organelles, phase separation, and intrinsic disorder. Current Opinion in Structural Biology, 44, 18 -30. https://doi.org/10.1016/j.sbi.2016.10.015

Vanderweyde, T., Yu, H., Varnum, M., Liu-Yesucevitz, L., Citro, A., Ikezu, T., Duff, K., Wolozin, B. (2012). Contrasting pathology of the stress granule proteins TIA-1 and G3BP in tauopathies. The Journal of Neuroscience: the official journal of the Society for Neuroscience, 32(24), 8270-8283. https://doi.org/10.1523/JNEUROSCI.1592-12.2012

Vanderweyde, T., Apicco, D. J., Youmans-Kidder, K., Ash, P., Cook, C., Lummertz da Rocha, E., Jansen-West, K., Frame, A. A., Citro, A., Leszyk, J. D., Ivanov, P., Abisambra, J. F., Steffen, M., Li, H., Petrucelli, L., Wolozin, B. (2016). Interaction of tau with the RNA-Binding Protein TIA1 Regulates tau Pathophysiology and Toxicity. Cell Reports, 15(7), 1455-1466. https://doi.org/10.1016/j.celrep.2016.04.045

Vashist, S., Cushman, M., Shorter, J. (2010). Applying Hsp104 to protein-misfolding disorders. Biochemistry and cell biology = Biochimie et biologie cellulaire, 88(1), 1-13. https://doi.org/10.1139/o09-121

Verdile, V., De Paola, E., Paronetto, M. P. (2019). Aberrant Phase Transitions: Side Effects and Novel Therapeutic Strategies in Human Disease. Frontiers in Genetics, 10, 173. https://doi.org/10.3389/fgene.2019.00173

Wang, Y., Mandelkow, E. (2016). Tau in physiology and pathology. Nature Reviews Neuroscience, 17, 5-21. https://doi.org/10.1038/nrn.2015.1

Wang, A., Conicella, A. E., Schmidt, H. B., Martin, E. W., Rhoads, S. N., Reeb, A. N., Nourse, A., Ramirez Montero, D., Ryan, V. H., Rohatgi, R., Shewmaker, F., Naik, M. T., Mittag, T., Ayala, Y. M., Fawzi, N. L. (2018). A single N-terminal phosphomimic disrupts TDP-43 polymerization, phase separation, and RNA splicing. The EMBO Journal, 37(5), e97452. https://doi.org/10.15252/embj.201797452

Wegmann, S., Eftekharzadeh, B., Tepper, K., Zoltowska, K. M., Bennett, R. E., Dujardin, S., Laskowski, P. R., MacKenzie, D., Kamath, T., Commins, C., Vanderburg, C., Roe, A. D., Fan, Z., Molliex, A. M., Hernandez-Vega, A., Muller, D., Hyman, A. A., Mandelkow, E., Taylor, J. P., Hyman, B. T. (2018). Tau protein liquid-liquid phase separation can initiate tau aggregation. The EMBO Journal, 37(7), e98049. https://doi.org/10.15252/embj.201798049

West, J. A., Mito, M., Kurosaka, S., Takumi, T., Tanegashima, C., Chujo, T., Yanaka, K., Kingston, R. E., Hirose, T., Bond, C., Fox, A., Nakagawa, S. (2016). Structural, super-resolution microscopy analysis of paraspeckle nuclear body organization. The Journal of Cell Biology, 214(7), 817-830. https://doi.org/10.1083/jcb.201601071 
Wilusz, J. E., JnBaptiste, C. K., Lu, L. Y., Kuhn, C. D., Joshua-Tor, L., Sharp, P. A. (2012). A triple helix stabilizes the 3 ' ends of long noncoding RNAs that lack poly $(A)$ tails. Genes \& Development, 26(21), 2392-2407. https://doi.org/10.1101/gad.204438.112

Wright, P. E., Dyson, H. J. (2015). Intrinsically disordered proteins in cellular signalling and regulation. Nature Reviews. Molecular Cell Biology, 16(1), 18-29.

https://doi.org/10.1038/nrm3920

Wyss-Coray, T. (2016). Ageing, neurodegeneration and brain rejuvenation. Nature, 539, 180-186. https://doi.org/10.1038/nature20411

Yamazaki, T., Nakagawa, S., Hirose T. (2020). Architectural RNAs for Membraneless Nuclear Body Formation. Cold Spring Harbor Symposia Quantitative Biology, 039404. https://doi.org/10.1101/sqb.2019.84.039404 